\title{
Improving L2 Writing Ability in the Light of Critical Thinking
}

\author{
Mostafa Morady Moghaddam \\ Ferdowsi University of Mashhad, Iran \\ Email: mostafa_morady@yahoo.com \\ Shirin Malekzadeh \\ Islamic Azad University of Urmia, Iran \\ Email: sh_malekzadeh196@yahoo.com
}

\begin{abstract}
With a cursory glance into the field of SLA, one can vividly recognize that the place of writing has been marginalized in comparison to other skills. Likewise, with the widespread implementation of communicative approaches to language teaching, writing has turned to a Cinderella skill in current EFL classes since most of the attention is paid to speaking and listening activities. However, improving writing ability has always been a concern for teachers, materials developers, and researchers. In this paper, the role of critical thinking (CT) in improving the writing ability of EFL learners was investigated. For this purpose, 70 EFL learners were asked to write a composition about a unique topic they had never thought before. A placement test was given to learners to divide them into proficient and less-proficient groups to see whether there is any variation between them. The common themes of the writings of these two groups were examined before introducing the principles of CT. After the first drafts of learners' compositions were gathered, all of the learners were taught some underlying principles of CT. The results showed that after explicitly teaching the principles of CT, learners' writings, in both groups, improved qualitatively and quantitatively; however, it had better effects on proficient learners. Background knowledge was also considered. It was revealed that having sufficient background knowledge is not the main key toward success in better writing. The findings proved that CT remained useful even when learners did not have any background information about the topic they were asked to write. Critical thinking was a way to provide learners with specific tools, namely, imaginative, supportive, and disciplinary. Finally, some recommendations are given.
\end{abstract}

Index Terms — critical thinking, writing skill, background knowledge, EFL learners

\section{INTRODUCTION}

As a great analogy, Brown (2001) likened writing to swimming. With more considerations, one can readily recognize the subtle commonalities that exist between these two skills. Writing is not an ability which is innately given to human beings and even when it is learned, there is a range of qualities as it is the case with swimming. No matter how excellent one swims, the sea will challenge even the best swimmers just like a writer who should always deal with a world of uncertainties. Writing sometimes becomes a nerve-racking activity even for native speakers. Here a thought-provoking statement by Brown (2001, p. 334) comes to forefront which stated that "What is it about writing that blocks so many people, even in their own native language"? Surely, the answer is not totally related to lexical or syntactic knowledge. A mature person is able to build complex structures and can understand or produce novel sentences which have never been heard before. S/he is also able to easily distinguish the nuances in a conversation between two individuals in his/her first language but writing a paragraph will be drudgery for him/her.

Researchers have endorsed the importance of writing skill in the success of learners. As Pecorari (2006) mentioned, "learning to write appropriate text is an essential component of academic success" (p. 5). There are many occasions that one needs to write as writing a letter or a composition, to name a few. Learners have a lot of problems dealing with writing skill and it is worthy to propose some solutions to reduce the problems. It requires a great deal of studies to find a way to remove some barriers of L2 writing skill. Therefore, it is important to improve learners' L2 writing skill so that they would be able to represent their thoughts at a satisfactory level.

Throughout the history of SLA, some methods and approaches toward language teaching have targeted the writing skill to show its nature and its intricacies. Whole Language proponents, for instance, advocated that "writing is not primarily as a means of demonstrating knowledge to a teacher, but a way of discovering for oneself what one thinks" (Rigg, 1991, p. 522). Maybe it is the process of thinking itself which render the task so cumbersome. Moreover, as it is mentioned by Cottrell (2005), it is difficult for many individuals to manage their thoughts in a logical and consistent way. Maybe the key to success in improving writing skill is laid outside the realm of linguistic elements. For solving the mystery of writing skill, other areas such as the ability to reason and logic may prove to be useful - two major aspects of critical thinking. 
When words such as discovering and introspection are highlighted in a particular activity, the role of thinking becomes much more obvious. Some researchers have stated that thinking and writing skill go hand in hand and are inseparable (Brown, 2001); therefore, the better one thinks, the better that person is going to deal with writing. Unfortunately, EFL curriculum is alienating itself from such important aspect of education-critical thinking. Moon (2008) believed that, "although thinking must surely be at the heart of education, it is not often explicitly taken into consideration in pedagogy" (p. vii). As learners grow up in their academic life, some crucial elements of education become much more outstanding though unknown to most learners and, disappointingly, to many educators. In order to think well, one should impose control and discipline on his/her thinking. This imposition is called critical thinking.

The importance of critical thinking has been addressed variously through educational life. Taylor and Mackenny (2008) stated that "critical thinking is a natural outgrowth of normal educational efforts" (p. 131). In Toward a postmethod pedagogy, Kumaravadivelu (2001) proposed the idea of "liberatory autonomy" in which the learners are empowered with critical thinking skills (p. 547). As the review of literature reveals, critical thinking is an underlying element of any educational effort and surely one cannot separate writing from critical thinking. According to Zamel (1982, p. 197), "writing is the record of an idea developing" in which individuals should manage their thoughts to come up with a consistent and coherent writing. Critical thinking is a subject of considerable current interest, both in terms of theory and pedagogy and most researchers have advocated the integration of critical thinking into other areas of foreign language learning (Bailin, Case, Coombs, \& Daniels, 1999).

Research on composition has traditionally been concerned with the written product (Zamel, 1982). This line of research mainly focused on the belief that a better pedagogical approach, particularly one that focused on usage, structure, or correct form, would improve writing (Zamel, 1982). However, with the advent of task-based approach and communicative language teaching, meaning and purpose gained importance. Witte and Faigley (1981) argued that the quality of compositions should be evaluated according to features of the text that extend across sentence boundaries. They believed that traditional approaches are too short-sided in order to distinguish the value of essays and besides explicit links within a text (cohesion), a text must conform to a reader's expectations for particular types of texts and the reader's knowledge of the world (coherence). Van Bruggen (1946) conducted a study in order to obtain a quantitative measure of the rate of flow of words during written expression and to determine what factors affect it and to discover differences in composing structure of superior and inferior compositions of pupils.

Crossley and McNamara (2009) examined how lexical differences distinguish between texts written by first and second language writers of English. They used two corpora one of them was essays written in English by native Spanish speakers and the other was a matching L1 corpus collected from undergraduate students. The results of this study revealed that L1 writers use more abstract and hierarchically connected words than L2 writers of English. In order to obtain this finding, they used a computational tool which was called Coh-Metrix.

Tuzi (2004) explored the relationship between electronic feedback and its impact on second-language writers' revisions. In this study Tuzi developed a database-driven web site and participants were required to write their essays in this web. Results of this study showed that learners prefer oral feedback but e-feedback proved to be more useful. The study focused on the role of online collaboration in improving writing skill. In another study which was conducted in this line of research, Gunel, Hand, and McDermott (2009) implemented a quasi-experimental design of a biology course. They used four groups of participating students and investigations aimed at finding the impact of writing-to-learn on students' understanding and the value of writing to different audiences. Bitcher, Young, and Cameron (2005) studied the effect of corrective feedback on L2 writing. Their study comprised 53 post-intermediate ESOL learners. The results of this study showed that different types of corrective feedback on three targeted linguistic errors helped learners improve the accuracy of their writing when producing new texts. Lee (2008) studied the relationship between writers' perceptions and their performance. Two tests were used in the study: a newly established FS test and an ESL placement test. The analysis of the relationships among the prompts, examinees' perceptions, and their performance showed that only the effects of the FS test prompts on students' perceptions were significant. The above-mentioned studies and so many similar investigations have shown how vast and complex the writing skill is. Although there have been considerable researches studying the nature of writing skill, interdisciplinary studies regarding the relationship between writing and other fields are not so welcomed.

The effect of critical thinking on writing skill is still ambiguous for most instructors and researchers. So many researchers have tried to find the answer of high-quality writing in the realm of linguistics ignoring the fact that writing is an interdisciplinary skill, as the line of research showed above, which interacts with various levels of thinking one of which is critical thinking. In this article we tried to find the effects of critical thinking on writing skill. Moreover, this study will shed some light on some difficulties that L2 learners encounter when dealing with writing skill.

\section{StATEMENT OF THE PRoBLEM}

- Writing skill challenges even the native speakers. Therefore, writing skill is not rooted just in linguistic competence.

- A mature person is able to build complex structures and can understand or produce novel sentences which have never been heard before. S/he is also able to easily distinguish the nuances in a conversation between two individuals in his/her first language but writing a paragraph will be drudgery for him/her. 


\section{METHOD}

\section{A. Participants}

To see whether critical thinking skills can help learners achieve better proficiency in their writings, 70 randomlychosen learners (41 female, 29 male) were investigated who were studying EFL in language institutes in Mashhad, Iran. They were mainly around 18 and the main textbooks of most of them were Passages and Interchange Third Edition. All of the learners were from the same native language (Persian). Among these learners, 39 were in less-proficient group and the rest 31 were proficient learners (according to their scores in a placement test). The average year of studying English for the learners was two.

\section{B. Procedure}

In order to investigate the effect of critical thinking on writing skill, all of the learners were given a paper in which there were presented a list of strange and unusual topics. Then, they were required to check those topics they had no idea about. The purpose was to choose topics that learners had not any background knowledge. We wanted to see whether lack of background knowledge can hinder learners continuing writing or they would improvise something.

When background knowledge on a specific topic is at minimum, learners have to resort to other devices which exist outside the realm of linguistic elements and the role of thinking will be much clearer. The titles which most learners selected as being unique were chosen. One of those titles - which was unique for the learners - along with a general topic was given to learners and they were asked to write three paragraphs for each. The motive behind giving learners a general topic was to consider whether having enough background information is the main key to success in writing skill and whether it leads to high-quality writings. There may be some arguments that if individuals know the background to a topic, they write better. The title, Problems of transportation, was given to learners to see whether background knowledge is the main concern in writing.

It should be mentioned that learners were taught right after the first draft of their writings were gathered. The teaching session did not postpone to another time, for there may be some enhancement in knowledge due to passage of time. Thus, there was no delay between the first draft and the second draft of the composition. The main interval was the teaching process which took about two hours and in this session some principles of critical thinking were taught. We gave some examples in order to make the point clear.

After the data were gathered, they were carefully investigated to gauge the quantity and quality of learners' writing. At the first level, all the compositions were gathered and they were studied. At the second level, all the learners were taught some underlying principles of critical thinking which are presented in Cottrell (2005, p. 2). They were used as the guidelines in order to familiarize learners with critical thinking processes. After this, learners were asked again to write a composition about the topic they had written once: You have three more days to live, what would you do in these three days? The compositions were gathered and they were compared with learners' first drafts. In order to consider the effect of background knowledge, the entire learners were given a very general topic for which all the learners had something to write. The data were examined and the results were compared using the two drafts of learners' writings.

\section{RESULTS AND DISCUSSION}

In the first phase of the study, we tried to find the quality of learners' writing. All of the learners were first given a list of peculiar and bizarre topics and they were asked to check those topics they had no idea about. There were ten topics included in the list. Table 1 shows the results of this investigation:

TABLE 1

THE DISTRIBUTION OF TOPICS AND ITS PECULIARITY ACCORDING TO LEARNERS' VIEW
\begin{tabular}{|l|l|}
\hline Topics & $\begin{array}{l}\text { Number of learners who } \\
\text { select the topic }\end{array}$ \\
\hline 1. Going to March & 70 \\
\hline 2. Future of Earth & 62 \\
\hline 3. Lost in the middle of a desert & 67 \\
\hline 4. Teaching a class full of noisy children & 60 \\
\hline 5. Winning a large sum of money in a lottery & 61 \\
\hline 6. Interviewing the president of your country & 70 \\
\hline 7. Traveling to a foreign country & 50 \\
\hline 8. Your plane encounter turbulence and drops & 67 \\
\hline 9. You have three more days to live & 70 \\
\hline 10. Lost in a jungle full of wild animals & 64 \\
\hline
\end{tabular}

As Table 1 reveals, most of the learners chose topics number 1, 6, and 9 as being unique and strange for them. Numbers 4, 5, and 7 were the topics marked as being more common to learners. They were asked to write a composition about the topic which was, "You have three more days to live, what would you do in these three days?" Learners had 15 minutes to finish their compositions. Learners' papers were gathered and were investigated. After giving the learners a placement test, we divided the data into proficient and less-proficient learners. The following are common themes gathered from learners' writing in these two groups before acquitting them with critical thinking: 

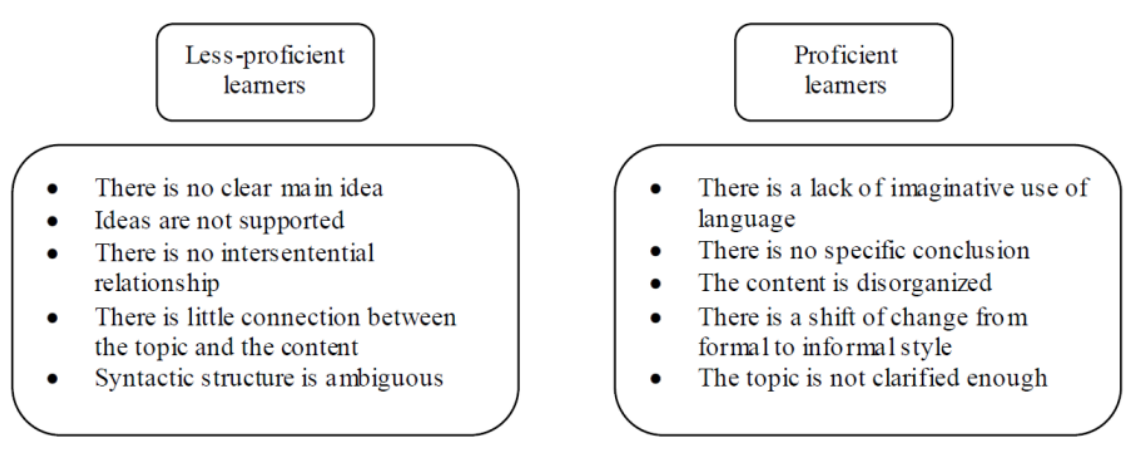

The common themes which were mentioned above are to some extent different regarding proficient and lessproficient learners. For proficient learners, problematic areas are more related to elements outside the realm of vocabulary and syntax. The problematic areas are mainly related to organizational factors, style, persuasive devices, and imaginative skills. Lexical and syntactic knowledge is more related to less-proficient learners. In general, problematic areas in both proficient and less-proficient groups are provided in Table 2:

TABLE 2

PROBLEMATIC AREAS IN LEARNERS' WRITINGS BEFORE TEACHING CRITICAL THINKING ABILITIES

\begin{tabular}{|l|l|}
\hline Category & Problematic areas \\
\hline Imaginative & $\begin{array}{l}\text { - Imaginative ability is ignored } \\
\text { - Truth value of sentences are mostly advocated } \\
\text { - Writings are not provided with open-minded expressions }\end{array}$ \\
\hline Supportive & $\begin{array}{l}\text { - The view points are not clarified } \\
\text { - The viewpoints are not verified or exemplified } \\
\text { - Main ideas are not supported } \\
\text { - Details are not provided } \\
\text { - Persuasive devices are not used }\end{array}$ \\
\hline Disciplinary & $\begin{array}{l}\text { - The whole text is disorganized } \\
\text { - There is no clear main idea } \\
\text { - Sentences are attached to each other purposelessly } \\
\text { - Syntax is ambiguous } \\
\text { - Style shifting is used in writings } \\
\text { - Language is not accurate } \\
\text { - Sentence connectors are not used }\end{array}$ \\
\hline
\end{tabular}

Learners' writings had some positive points too. For instance, some of the learners understood the topic well and they did not deviate from the main points. There were some errors but the writings were comprehensible above all. The topic is "you have three more days to live." Learners are asked to write a composition about what they would do in these three days (Case 1a, one of the learners' writings before teaching the principals of critical thinking):

Case 1a (The composition before teaching the principles of critical thinking)

You have three more days to live

Every time should be ready to die. I go to a holy shrine or mosque. I want God to forgive my sins. I ask people around me to forgive me. I believe the best things to do to be kind with people and helping to them. Because every thing is died except good deeds. Then I thank my parents and family because all of their kinds. I wanna happy them. The last point is I ask God forgive my sins because of his kindly. And I am kind to people and my friends.

The example in Case 1a shows some problems which were mentioned earlier in this paper. Sentences are short and the whole composition is not well-organized. Sentences are attached to each other arbitrarily, without any relationship between them. The learner has used wanna which is an informal way of saying want to. This shift of style is one of those problematic areas mentioned earlier and learners should be explicitly taught not to use informal structures in their writings.

In the next phase, we taught all the learners using four underlying principles which are mentioned below. As it is mentioned in Cottrell (2005), there are some underlying principles that can foster better critical thinking abilities:

- Evaluating the evidence for alternative points of view. This requires seeing one issue from different glasses to come up with new ideas. In other words, a writer should be able to read between the lines, seeing behind the surface. This would make the composition eye-catching and outstanding since it contributes something new, something from nowhere but existing.

- Weighing up opposing arguments and evidence fairly. This means that a writer should put the prejudices aside and evaluate different view points in a clear way. This would surely help the writer to have an open mind which allows the information to come to his/her mind. For example, it is helpful to form arguments in the writing. One case in point is the use of opposite views in writing. A good writer always considers different viewpoints of a particular event or activity. In a particular topic, for instance, one may write about this idea that "We should increase prison sentences for crime." Another argument which may add to the quality and quantity of writing is forming counterarguments. For instance, in 
the previous sentence, one can use the following sentence as a way of expanding the thought: "Increasing prison sentences is not helpful" (Cottrell, 2005). It is a suitable way to increase the writing skill and this requires the writer to put his/her prejudices aside and form fruitful arguments. Geertsen (2003) mentioned that "proper attitude shapes good thinking" and further defined the proper attitude as having an open mind. He stated that in order to see hidden and unnoticed places, an open mind is necessary (p. 5).

- Recognizing techniques used to make certain positions more appealing than others, such as false logic and persuasive devices. A good writer always tries to convince the reader by using some examples or by giving some statistics and the like. This would insure the reader that what is written is not a junk good for the trash can. Some of these devices that can make the writing as colorful as possible are, "poems," "numbers," "scientific sentences," "expressions," "personal experiences," "words of the eminent people," and "common belief," to name a few.

- Presenting a point of view in a structured, clear, well-reasoned way that convinces others. A good strategy to write a composition is to bring order to the information. That is, the data should not be presented on the paper in a haphazard fashion. This would surely bring confusion to the reader. The writer should keep the flow of writing in a clear way like a soap opera. Every paragraph should be dedicated to one point and different ideas should not be mixed without any link between them since writing is not like a hotchpotch to be served. Using some formulaic writing can help writers to present a more academic composition which is appealing to the eyes of the reader. Sentences such as, recently, it has been suggested that... makes the composition more meaningful and organized.

After teaching these principles, all of the learners were asked to write the composition again. Learners were familiarized with some principles of critical thinking and they were given some examples to make the point clear. When the teaching session finished, they were asked to write about the same topic they had written once. There was no delay between the first draft and the second draft but the teaching process itself. This would reduce the effect of knowledge which is likely to increase due to passage of time. The following writing is from the same learner his writing was presented in Case 1a. This is about the same topic but after teaching the principles of critical thinking (Case 1b):

Case $1 \mathrm{~b}$ (The composition after teaching principles of critical thinking)

You have three more days to live

The first thing that I think is necessary and vital for me is that I would go to holy shrine or mosque and say pray at there. Because these are the first things that will come to help you there when you are in front of God. You know what because I think that the forgiveness of God is necessary I try to worship and adore and say to God forgive me. God is so kind and will forgive my sins.

The second thing that is important it can be people who are around me. I want do the something that I say to God. I want people to forgive me and try to relent and don't be strict about what I has done before. And the guys can be my parent at first and then my brother and sister and relatives and my intimate friends. I try to do good things for them and try to make them happy.

The last one I should do, is that enjoy myself and have fun in three days that I think two day take time for forgiveness and just 1 day left. In one day I try to be friendly and sociable with people and the guys around me and I went to be lovely.

It is obvious that, comparing the two writings of Case $1 \mathrm{a}$ with Case $1 \mathrm{~b}$, both the quality and quantity of writing have increased to a considerable degree. The information is more organized and the learner's point of view is more vivid (disciplinary tools of critical thinking). The learner has organized his writing by categorizing each paragraph using words such as the first, the second, and the last. The learner, his two drafts are presented above, was able to improve the quality of his writing and make it more appealing just after he was taught the principles of critical thinking. In the second draft, the learner has used some persuasive devices to convince the reader that he is right and to support his ideas (supportive tools). It is one of the principles of CT which was about recognizing techniques used to make certain positions more appealing than others, such as false logic and persuasive devices:

"Because these are the first things that will come to help you there..."

Moreover, in the second draft, the learner has come to a new insight, to enjoy himself (using alternative view points). This idea is in contrast with the idea of death. Usually the term (death) brings with itself a kind of regret and misery but this learner is going to enjoy life and to forget dying altogether (imaginative tools).

After all the data were investigated, common themes of learners' writings were found and categorized under specific headings. Most of these changes are related to clarifying the writings and organizing the paragraphs with providing specific tools. Table 3 refers to common themes of learners after teaching the principles of critical thinking: 
TABLE 3

COMMON THEMES IN LEARNERS' WRITINGS AFTER TEACHING CRITICAL THINKING PRINCIPLES

\begin{tabular}{|l|l|}
\hline Category & Problematic areas \\
\hline Imaginative & $\begin{array}{l}\text { - Imaginative ability is considered } \\
\text { - More open-minded sentences are used }\end{array}$ \\
\hline Supportive & $\begin{array}{l}\text { - The viewpoints are verified or exemplified } \\
\text { - Different view points are considered }\end{array}$ \\
\hline Disciplinary & $\begin{array}{l}\text { - Writings are categorized in different paragraphs } \\
\text { - Use of conjunctions are more common } \\
\text { - The main idea is clear } \\
\text { - Sentences are clearer } \\
\text { - Sentences are attached to each other purposefully }\end{array}$ \\
\hline
\end{tabular}

Below is presented another composition from another learner. The results remained the same for this learner too. The following compositions make the point clear (Case 2a, learner's composition before teaching the principles of critical thinking):

Case $2 \mathrm{a}$ (The composition before teaching the principles of critical thinking)

You have three more days to live

If I would have three more day to live, I will do all the things that I wanted to do. I travel around the world and go to sight seeing. I go to the nature and speak to God.

One point that we may think about it, is our sins and wrong deeds. What can we do in this short time? Just small things satisfying people and being kind to them and giving back the money or other things that I had borrowed. I asking God to forgive us.

I would do good deeds and being kind with others especially with our parents. In a testament I give my things to family. Then I make myself ready to leave this world.

It is clear that the same problems which were observed in Case 1a can be seen in Case 2a. The learners mostly tried to see the point realistically without considering various points that are relatable to the topic (lack of imaginative power). For instance, Case 2 a shows that the learner has adhered to truth value of sentences. Two issues she has mentioned are doing good deeds and respecting others. It would be of interest to use some imaginative sentences to make her writing more appealing. It is also obvious that paragraphs are too short. There is not a good conclusion at the end of the writing and it may be realized that she has just written what has come to her mind without organizing them (lack of disciplinary power). The following is from the same learner her writing was presented in Case 2a. After teaching some underlying principles of critical thinking, she was given the same topic and she was asked to write three paragraphs about it. The following represents her writing (Case 2b):

Case $2 \mathrm{~b}$ (The composition after teaching principles of critical thinking)

You have three more days to live

Being alive just for three days. If I know that I'm alive just for three days, I try to do all the things that I wish to do in my life. I always want to travel around the world and see beautiful places all over the world but because I'm not alive more than three days I can't do it and go inside the nature and think about myself and speak with God to forget dying.

I also try to be kind with people even more than before. I should be very careful with people around. For example I should give back the money I borrowed from people. It is very important for me. Others view toward me is very important. If they are unhappy about me I should satisfy them.

Finally, I write a testament and give my things to my family and my friends. If I had a problem with somebody and solve it and want to forgive me. I try to get ready for die mentally and physically. I must accept it and be ready to leave this world and all the things that are related to this world. I ask God forgive me for all my sins.

Comparing the two writings in Case $2 a$ with Case $2 b$, it is clear that in Case $2 b$ the content is more organized and there is more clarification of ideas (supportive tools). Use of words such as finally and also (structured writing) reveals that the learner has tried to connect the paragraphs to each other to increase the organization of the writing (disciplinary tools). The concept of beautiful places (opposing arguments) is not compatible with the concept of dying which is included indirectly in the topic. However, the learner has used her imaginative power to increase the quality of her writing. Supportive tools will contribute to the improvement of writings quantitatively. The learner has used some persuasive devices too. To forget dying is the phrase which is used to give the reason why it is needed to go to the nature and speak with God. In addition, the learner has used I must accept it to relieve herself. The sentence because I'm not alive more than three days I can't do it, is used to show that traveling is not possible since there is not enough time to do so.

Background Knowledge vs. Critical Thinking

As it was mentioned earlier, a general common-sense topic was given to learners for which they were supposed to have background knowledge. The results showed that even in general topics, principles of critical thinking can be beneficial. With a comparison between the first drafts and the second drafts of the writings above, it is clear that the second drafts (after teaching the critical thinking skills) of learners' writings are more organized and the information is presented more clearly. In addition, writings are richer regarding supportive, imaginative, and disciplinary skills. The findings showed that explicitly teaching the principles of critical thinking can bring considerable change to learners' 
writings. The following are two drafts of a learner's composition about the Problems of transportation. (Case 3a, a general topic is proposed and learners are asked to write three paragraphs about that):

Case $3 \mathrm{a}$ (The composition before teaching the principles of critical thinking)

Problems of transportation

The first problem is the system which is unorganized. The incorrect organization system of traffic time and street is not standard for vehicles. There are many old vehicles in city. There are so many people in bus stops and it took a lot of time they come. The road is also a problem. Roads outside the cities are too dangerous and it causes accident.

Every days factories are producing new cars and over producing of cars are problems to transportation. People be used to use the private car and another point is over using of vehicles for transportation and the lack of public vehicles for use.

In Case 3a, there is little organization between paragraphs. Furthermore, sentences are combined with each other without any relationship between them. The opinions are not clarified and there is no example to persuade the readers. With administrating the four principles of critical thinking, the learner was able to write the following passage. (Case $3 \mathrm{~b}$, the same learner his writing was analyzed in Case $3 \mathrm{a}$ is asked to write the same writing but this time after teaching the principles of critical thinking):

Case $3 \mathrm{~b}$ (The composition after teaching the principles of critical thinking)

Problems of transportation

One of the most important problems is an unorganized system. I think if we improve our organization we could solve our problems. For example if we consider the number of vehicles, population and jam we could have better public transportation.

The second problem is old vehicles that use in the city and the number of them. It's not sufficient for the population and most of the times a lot of people standing at taxi and bus stops and waiting for a long time especially in certain times of the day that the streets are busy it is worse. Cars should be reduced otherwise the people will be reduced as the result of pollution. We can replace old vehicles with new ones.

The third problem is road. A lot of our roads between cities are one way and it's too dangerous and causes a lot of bad accidents. They must change and be more safty. In cities we don't have standard roads and most of the times cause bad accidents.

After teaching some underlying principles of critical thinking, learners take more time to contemplate the topics. When asking learners to write about a general topic, Case 3a, they were supposed to have enough information in their minds. However, even with enough background knowledge, some problems occurred. It was revealed that critical thinking skills influenced the quality of writings. Explicit teaching of critical thinking strategies had great effects on learners' writing. One of the critical thinking principles, which is organizing information, helped learners to classify and organize their thoughts; this is clear in Case 3b, in which the learner has used phrases such as one of the most important problems, the second problem, and the third problem. The sentence especially in certain times of the day that the streets are busy, is used as a persuasive device. From this example we can conclude that background knowledge is not the main road to success in L2 writing skill. An individual may have enough background knowledge and may be familiar with the topic, but presenting the information in an acceptable and precise manner is not in the scope of familiarity with the topic. It does not mean that background knowledge is completely useless, but it should be attached to other fields such as critical thinking skills in order to present a fine piece of writing. The learner has used alternative viewpoints in Case $3 \mathrm{~b}$. The sentence the people will be reduced as the result of pollution, is used to show that cars are dangerous for peoples' health since they produce gases which pollutes the air. The learner has related the two concepts in a smart way to convey the meaning in an appealing manner.

The principles of critical thinking had better effect on proficient learners since they were more cognitively ready and their better underlying linguistic system helped them get the most out of the feedbacks they received. For instance, proficient learners were ahead of the others (less-proficient learners) in using sentence connectors, forming counterarguments, providing conclusion, providing details, using persuasive devices, using imaginative tools, and categorizing information. This superiority may be the result of their higher sensitivity to feedback they received during the session in which some principles of critical thinking were taught. Since proficient learners can benefit more from the input they receive, the feedback had better effects on them.

\section{CONCLUSION}

In this study we tried to investigate the effects of critical thinking on improving learners' L2 writing skill. During the first phase of the study, learners were asked to write a composition about an unknown topic and then the writings were studied carefully. In the next phase, learners were explicitly taught some principles of critical thinking skills immediately after they have finished the first draft of their writings. Most of the learners had a considerable improvement both qualitatively and quantitatively. However, critical thinking principles were more useful for proficient students since they are cognitively much ahead of the others and this positive point helped them to be more sensitive to the input and feedback. Moreover, after teaching the principles of critical thinking, learners' composition enjoyed much more discipline and order. In general, critical thinking provided learners with three powerful tools which proved to be useful in improving L2 writing skill. These tools are: 
- Imaginative (e.g., counterarguing, open-minded views)

- Supportive (e.g., giving examples, clarification of ideas)

- Disciplinary (e.g., clear main ideas, paragraph organization)

Besides critical thinking, in order to improve L2 writing skill, it is helpful to take into account the following recommendations which were driven from the results of this study:

- Learners should reflect on an issue or happening

- Learners should analyze their classmates' writings

- Learners should synthesize new and incomplete ideas and information

- Learners should take into account the reader when they write

- Teachers should explicitly explain the differences between critical thinking and thinking

- It is good to manage workshops in which learners can extend their thinking

- Learners should be taught to compare and contrast their thoughts with various perspectives

It should be mentioned that one cannot put all the responsibilities of better L2 writing skill on the shoulder of critical thinking. Writing is a skill which is related to many fields critical thinking is only one of them. However, through teaching the principles of critical thinking, learners are more likely to overcome some of the problems that they will encounter in the process of writing. As it was mentioned in this study, learners were able to organize their compositions after they were acquainted with critical thinking skills and their implications. Moreover, learners' compositions were much clearer and void of undue ambiguities in the second draft. There were some learners who came up with new insights. The effect of drafting itself should not be underestimated. The process of drafting may have some effect on the learners' compositions; however, the changes are more related to the principles of critical thinking.

Authorities and teachers can bring change to the teaching of L2 writing skill by integrating critical thinking skills into the writing system of a foreign language. Teachers also can help learners increase their insights so that they would be able to be judges of their own writings. To put it in a nutshell, teaching L2 writing can go further than considering the linguistic elements. Increasing learners' consciousness and higher-level thinking processes can improve learners' proficiency in dealing with writing and even with other aspects of L2 competence.

\section{REFERENCES}

[1] Bailin, S., Case, R., Coombs, J., \& Daniels, L. (1999). Common misconceptions of critical thinking. Journal of Curriculum Studies, 31(3), 269-283.

[2] Bitcher, J., Young, S., \& Cameron, D. (2005). The effect of different types of corrective feedback on ESL student writing. Journal of Second Language Writing, 14, 191-205.

[3] Brown, H. D. (2001). Teaching by principles: An interactive approach to language pedagogy. Englewood Cliffs, NJ: Prentice Hall Regents. ( $2^{\text {nd }}$ ed.). White Plains, NY: Longman.

[4] Cottrell, S. (2005). Critical thinking skills: Developing effective analysis and argument. Palgrave Macmillan Ltd.

[5] Crossley, S. A., \& McNamara, D. S. (2009). Computational assessment of lexical differences in L1 and L2 writing. Journal of Second Language Writing, 18, 119-135.

[6] Geertsen, R. H. (2003). Rethinking thinking about higher-level thinking. Teaching Sociology, 31(1), 1-19.

[7] Gunel, M., Hand, B., \& McDermott, M. A. (2009). Writing for different audiences: Effects on high-school students' conceptual understanding of biology. Learning and Instruction, 19, 354-367.

[8] Kumaravadivelu, B. (2001). Toward a postmethod pedagogy. TESOL Quarterly, 35, 537-560.

[9] Lee, H. (2008). The relationship between writers' perceptions and their performance on a field-specific writing test. Assessing Writing, 13, 93-110.

[10] Moon, J. (2008). Critical thinking: An exploration of theory and practice. NY: Routledge.

[11] Pecorari, D. (2006). Visible and occluded citation features in postgraduate second-language writing. English for Specific Purposes, 25, 4-29.

[12] Rigg, P. (1991). Whole Language in TESOL. TESOL Quarterly, 25(3), 521-542.

[13] Taylor, G. R., \& Mackenny, L. (2008). Improving human learning in the classroom: Theories and teaching practices. NY: Rowman \& Littlefield Education.

[14] Tuzi, F. (2004). The impact of e-feedback on the revisions of L2 writers in an academic writing course. Computers and Composition, 21, 217-235.

[15] Van Bruggen, J. A. (1946). Factors affecting the regularity of the flow of words during written compositions. Journal of Experimental Education, 15, 133-155.

[16] Witte, S. P., \& Faigley, L. (1981). Coherence, cohesion, and writing quality. College Composition and Communication, 32(2), 189-204.

[17] Zamel, V. (1982). Writing: The process of discovering meaning. TESOL Quarterly, 16(2), 195-209.

Mostafa Morady Moghaddam: M.A. student in Teaching English as a Foreign Language (TEFL), studying at Ferdowsi University of Mashhad, Iran. He got his B.A. in TEFL at Islamic Azad University of Mashhad, Iran. He has written some papers on the nature of interactions and group work among children and he is interested in cultural, social, and psychological studies regarding foreign language learning. 
Shirin Malekzadeh: M.A. student in Teaching English as a Foreign Language (TEFL), studying at Islamic Azad University of Urmia, Science and Research Branch, Iran. She got her B.A. in TEFL at Islamic Azad University of Mashhad, Iran. 